\title{
Disseminated hexamitosis in sea-caged Atlantic salmon Salmo salar
}

\author{
T. T. Poppe ${ }^{1}$, T. A. Mo ${ }^{2}$, L. Iversen ${ }^{3}$ \\ ${ }^{1}$ Norwegian College of Veterinary Medicine, POB 8146 Dep, N-0033 Oslo 1, Norway \\ ${ }^{2}$ National Veterinary Institute, POB 8156 Dep, N-0033 Oslo 1, Norway \\ ${ }^{3} \mathrm{~N}-9500$ Alta, Norway
}

\begin{abstract}
A flagellated parasitic protozoan, similar to Hexamita salmonis, was found in large numbers in all internal organs, except muscle, in diseased sea-caged postsmolt Atlantic salmon $(200$ to $250 \mathrm{~g}$. In postsmolts, whitish granulomatous nodules, containing large numbers of Hexamita sp., were present in kidney and liver. In large salmon ( 4 to $5 \mathrm{~kg}$ ), the most severe lesions were boils in caudal muscle. These unusual cases of hexamitosis were recorded at 4 fish farms in northern Norway (approximately $70^{\circ} \mathrm{N}$ ). No bacteria or virus that could be linked to the disease were demonstrated.
\end{abstract}

\section{INTRODUCTION}

The flagellated parasitic protozoan Hexamita salmonis Moore, 1922, has been found in the gut of salmonids in freshwater in many countries (e.g. Sano 1970, Ferguson 1979, Lom 1984, Poynton 1986, Poppe 1990, Poynton \& Morrison 1990). Problems due to this parasite are mainly seen in fingerlings during warm periods in the summer. Characteristic signs include anorexia, dark coloration, and faecal pseudocasts. This parasite does not seem to occur commonly in Norway, and has been found only in some hatcheries and occasionally in feral salmonids during summer.

In November 1989, increased morbidity and mortality were noted in a cage of postsmolt Atlantic salmon Salmo salar L. (200 to $250 \mathrm{~g})$ in a sea-water fish farm in northern Norway $\left(70^{\circ} \mathrm{N}\right.$ ) (Mo et al. 1990). In fish investigated at the farm, large numbers of highly motile hexamitid flagellates were observed in the blood and in whitish nodules in liver and kidney. Live salmon were submitted to the National Veterinary Institute for investigation and identification of the parasite. Similar observations were made at 2 other fish farms, one in December 1989 and one in October 1990. In June 1991, boil lesions restricted to the caudal musculature were noted in large fish (4 to $5 \mathrm{~kg}$ ) at a fourth farm during slaughtering. The lesions were red-brownish in colour and contained large numbers of flagellated protozoans. The observations made on these 4 unusual cases of hexamitosis are presented here.

\section{MATERIALS AND METHODS}

Case Farm A. This fish farm is situated near Alta in northern Norway (Fig. 1). The water temperature was about $6^{\circ} \mathrm{C}$ and the salinity was about $31 \%$ in late November 1989, when 9 live salmon (200 to $250 \mathrm{~g})$ were shipped by air for investigation at the Fish Disease Laboratory, National Veterinary Institute (NVI). The smolts had been put out into the sea in August 1989. Most of the fish had been feeding actively until they were sorted out for investigation.

Parasitology: The fish were killed by a blow to the head. Coverslip-covered smears and imprints were made from blood drawn from the caudal vein and from all internal organs. From organs with macroscopically visible lesions, the imprints were made from the lesions. The fresh smears and imprints were examined in a phase-contrast microscope. Smears and imprints were also made from the same organs for staining. The slides were air-dried, fixed in $100 \%$ methanol for 5 min and stained with Leishman/Giemsa and Wilder's silver impregnation stain according to Culling et al. (1985) before examination in a light microscope. 


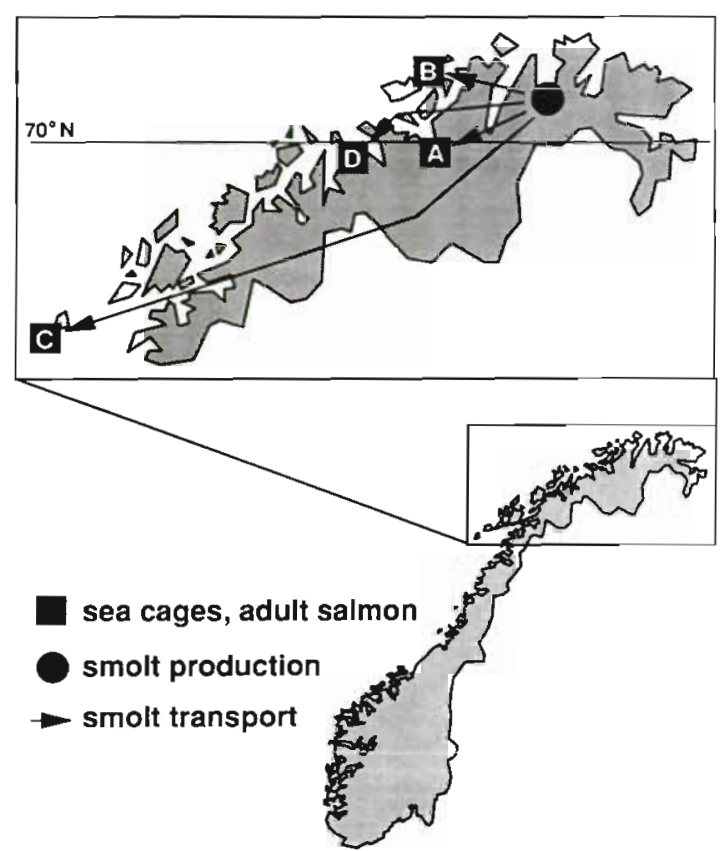

Fig. 1. Locations in Norway of 4 salt-water fish farms (A to D) where hexamitosis has been diagnosed and of the hatchery supplying smolts to the farms

Sections from gills, heart, brain, kidney, liver, pyloric caeca with pancreas, spleen, swim bladder and muscle were taken from the autopsied fish and fixed in $10 \%$ neutral-buffered formalin. The tissue specimens were processed routinely for histology, $5 \mu \mathrm{m}$ paraffin wax sections being stained with haematoxylin and eosin $(\mathrm{H} \& \mathrm{E})$, Periodic Acid-Schiff (PAS), Gram, Ziehl Nielsen, Wilder's silver impregnation stain, and Lillie's allochrome (Culling et al. 1985).

Sections from swim bladder for scanning electron microscopy (SEM) were taken from the same fish and fixed in $3 \%$ glutaraldehyde in $0.1 \mathrm{M}$ buffer. The SEM samples were dehydrated in an ethanol series to $100 \%$, critical point $\mathrm{CO}_{2}$-dried, coated with gold in a Polaron sputter, and viewed in a Cambridge Stereoscan.

Microbiology: For bacteriology, samples were taken from the lesions in the kidney and liver and cultured on blood agar, $2 \% \mathrm{NaCl}$ supplemented blood agar and a selective Kidney Disease medium (S-KDM) (Austin et al. 1983). The blood agar plates were incubated at 15 and $22^{\circ} \mathrm{C}$ for $4 \mathrm{~d}$ while the S-KDM plates were incubated at $15^{\circ} \mathrm{C}$ for up to $3 \mathrm{wk}$.

For virology, samples were taken from mid-kidney and treated according to standard procedures with incubation at $15^{\circ} \mathrm{C}$ on RTG-2 cells for $2 \times 10 \mathrm{~d}$.

Case Farms B, C and D. These fish farms are situated near Sørøya (Farm B), near Værøy (Farm C), and near Nordreisa (Farm D) in northern Norway (Fig. 1). The diseased salmon were investigated in December 1989, October 1990, and June 1991, at Farms B, C, and D, respectively. The water temperature and salinity at each farm was about the same as for Farm $A$, except that the water temperature at Farm D was about $10^{\circ} \mathrm{C}$. Between 5 and 10 fish were examined on the fish farms by local veterinarians. Smears and imprints were made from internal organs. Formalin-fixed tissues was sent to NVI for histological verification. One slaughtered adult salmon from Farm D was sent to NVI for investigation of boils in the caudal muscle.

The nomenclature of the condition is made in accordance with the guidelines given by Kassai et al. (1988).

\section{RESULTS}

\section{Case Farm A}

Macroscopic observations. The diseased fish were in normal bodily condition, although significantly smaller than other fish in the same age-group on the same fish farm. The salmon were infested with a few sea lice, mostly Lepeophtheirus salmonis, though a few Caligus elongatus were also found. No external lesions were noted.

In most fish, the colour of the liver was lighter than normal. Two fish had prominent whitish nodules on the liver surface (Fig. 2a) and in the posterior part of the kidney (Fig. 2b). The nodules were easily scraped off, leaving a soft, haemorrhagic crater. The contents of the posterior gut was more fluid than normal with a greenish colour. Three fish showed extensive haemorrhage in the cerebral meninges.

Microscopic observations. Large numbers of highly motile, flagellated hexamitid protozoans could be demonstrated in fresh blood smears, and in fresh imprints from the whitish nodules and all organs except muscle. (Three months later, in January 1990 , they could also be demonstrated in boils in the muscle, mainly in the caudal region.) Typically, the hexamitid protozoans were pear-shaped with 6 anterior and 2 posterior flagella, and were slightly smaller 16 to $8 \mu \mathrm{m}$ long) than red blood cells. The SEM study of the swim bladder was complicated because of interference with particles, probably inflammatory cells and cell debris. A large number of trophozoites of a flagellated hexamitid protozoan were found, but the flagellar bases could only be studied in a few specimens. This showed that the parasite has anterior lateral flagellar bases and a blunt end with the 2 recurrent flagella emerging posteriorly (Fig. 3). Thus it belongs to the genus Hexamita and not Spironucleus which has anterior medial flagellar bases and a pointed posterior end with the recurrent flagella emerging postero- 
a

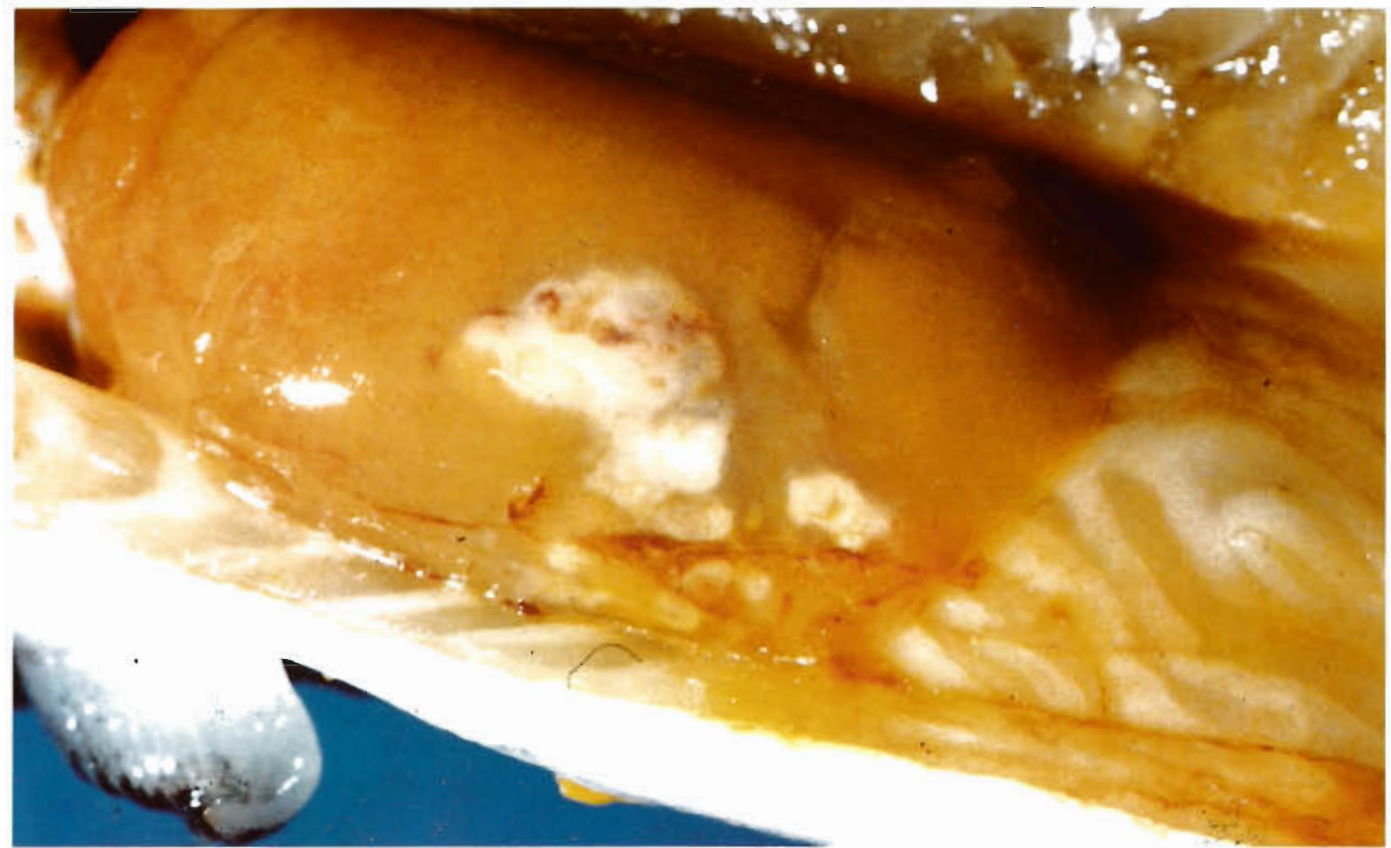

$\mathrm{b}$

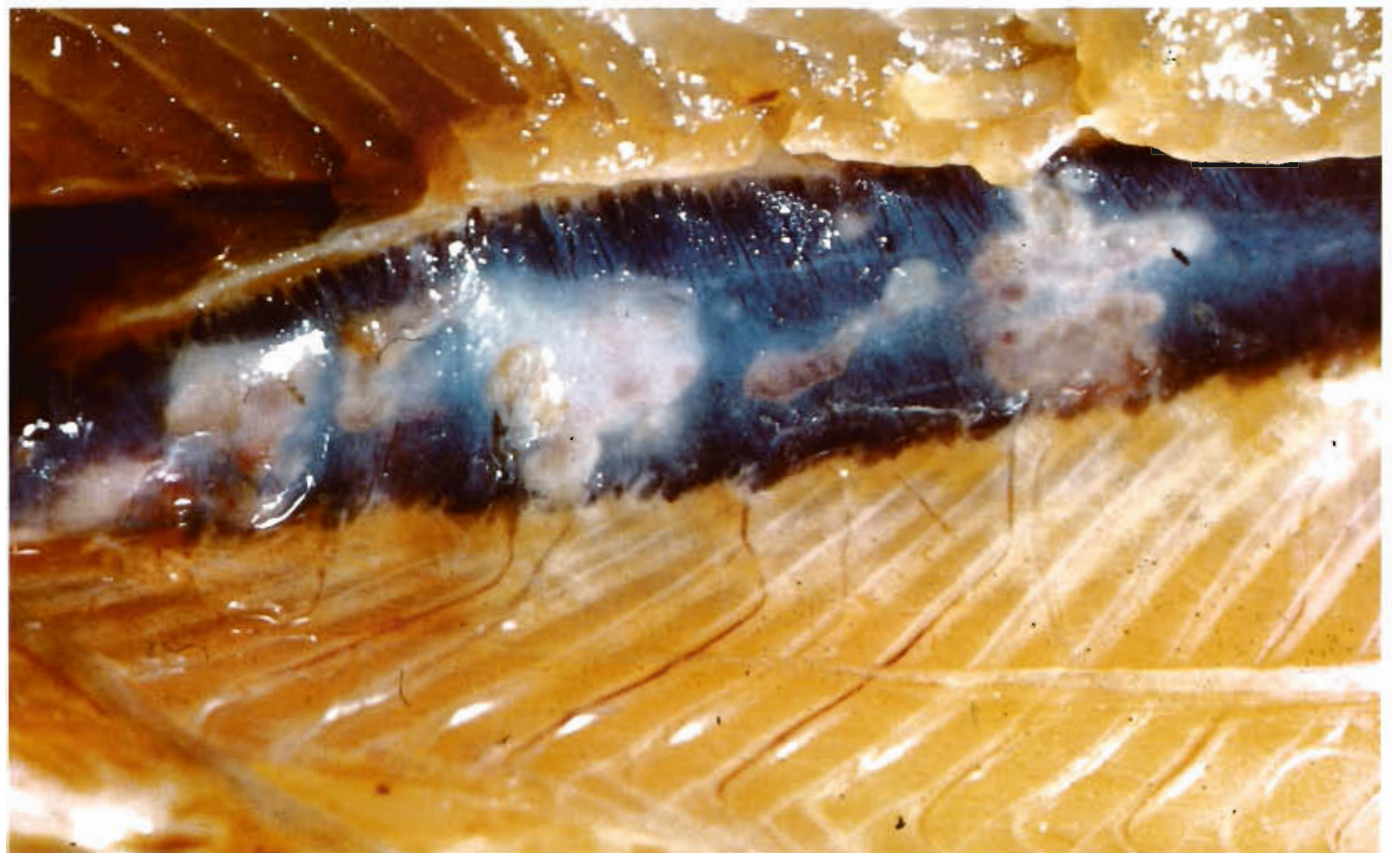

Fig. 2. Salmo salar. Atlantic salmon with hexamitosis; granulomatous lesions in (a) liver, (b) kidney

laterally (Sarah Poynton pers. comm.) So far, we have not been able to differentiate the Hexamita sp. from $H$. salmonis in SEM photos presented by Ferguson (1979) and Poynton \& Morrison (1990), except that the distance between the 2 posterior flagella at the bases seems to be larger in Hexamita sp. than in the earlier published SEM photos of $H$. salmonis. It is not known whether this distance can be of taxonomical importance.
The flagellated hexamitid protozoans could also be demonstrated in stained smears and imprints. In these, the parasites were easily recognized by the darkly stained paired anterior nuclei (Fig. 4).

Histopathology. Histological investigations of the liver and kidney revealed multifocal areas of coagulative and caseous necrosis. Centrally in the lesions, there was total loss of normal architecture, while there was edema, congestion and haemorrhage in 


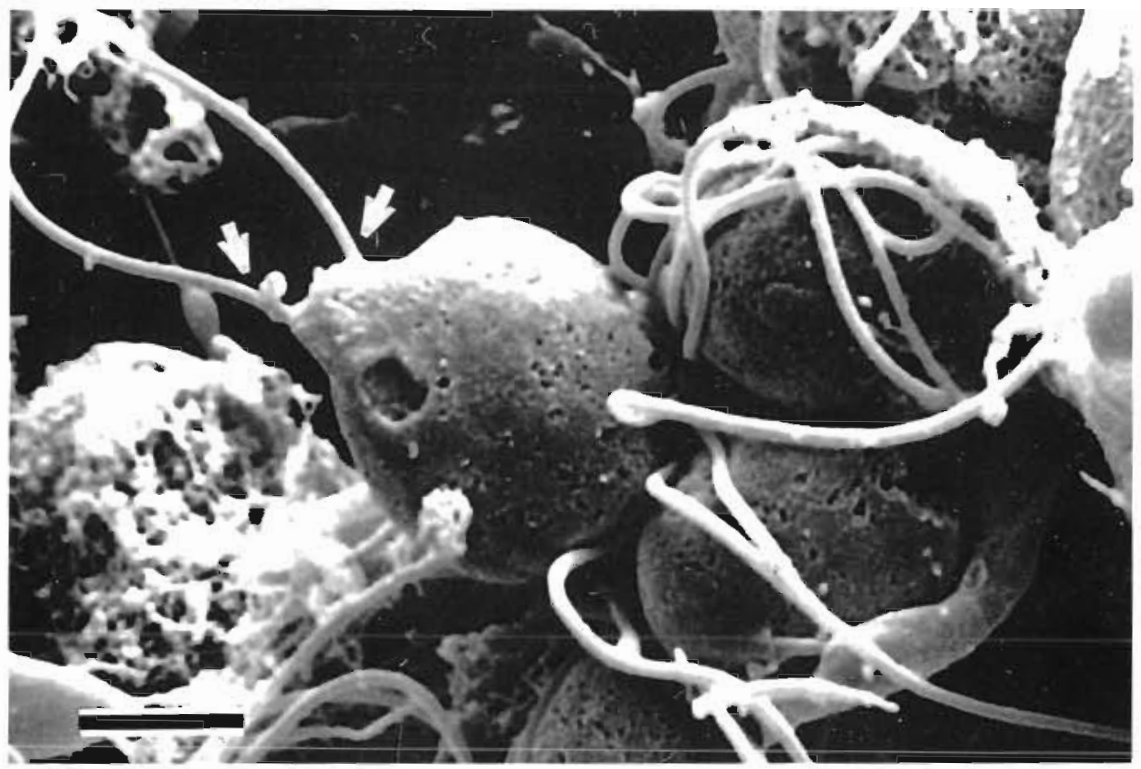

Fig. 3. Salmo salar. SEM photo of Hexamita sp. in swim bladder showing the 2 posterior flagella emerging posteriorly from the blunt end (arrows). Scale bar = $2 \mu \mathrm{min}$

the periphery. In general, these lesions were restricted to areas with grossly visible organ changes. Inflammatory response was lacking in many of the affected areas, while others demonstrated a chronic granulomatous response with substantial fibrosis. Throughout the necrotic areas and mixed with necrotic debris, there was a large number of oval, pear-shaped or rounded eosinophilic cells that could not be classified. These cells had the same size and shape as the cells found in the stained imprints. There was extensive cholangiohepatitis with peribiliary lymphoid hypercellularity and some fibrosis in advanced cases. There was also widespread fibrinous perihepatitis. The PAS and Gram stains did not reveal any sign of bacterial or fungal infection. Most of the fish had severe muscular degeneration, but no inflammatory or parasitic cells were found in the muscle. In the brain sections, random multifocal

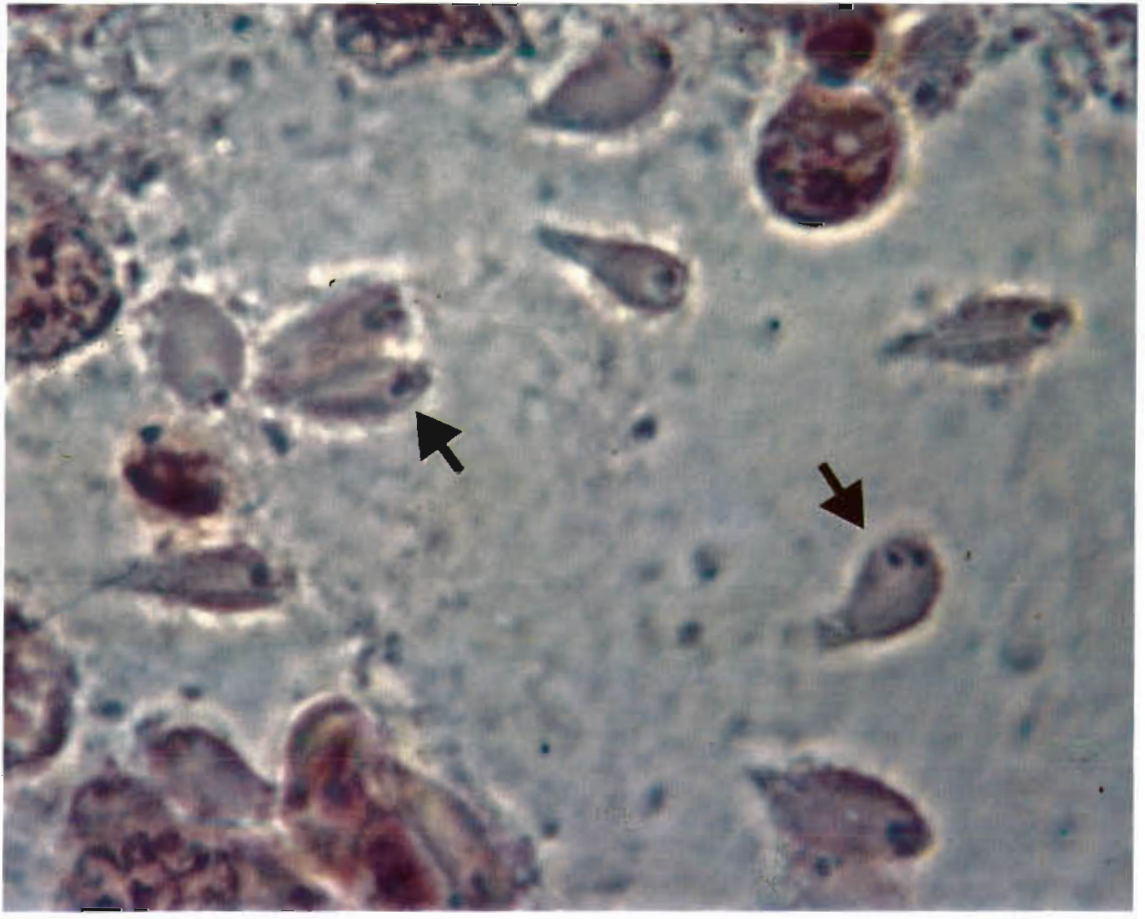

Fig. 4. Salmo salar Imprint of liver stained with Wilder's silver impregnation showing several hexamitid flagellates with paired anterior nuclei (arrows). $\times 1000$ 


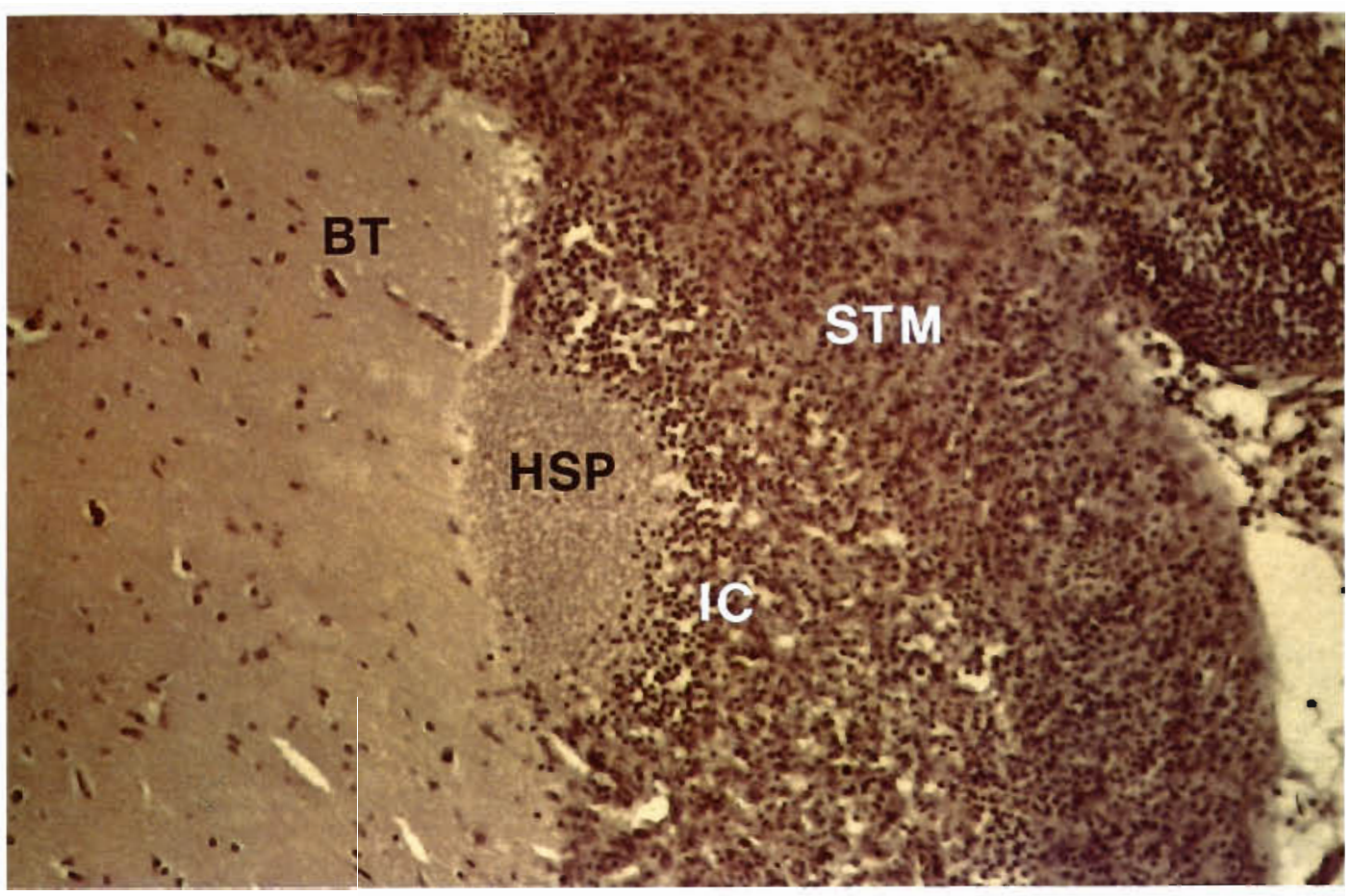

Fig. 5. Salmo salar. Micrograph of $\mathrm{H} \& \mathrm{E}$ stained section of brain. BT: brain tissue; HSP: monoculture of Hexamita sp.; IC: inflammatory cells; STM: severe thickened meninges. $\times 100$

areas of encephalitis and suppurative meningitis with the same flagellated protozoans present could be seen, often surrounded by large numbers of neutrophilic granulocytes and lymphocytes (Fig. 5). Quite often, the parasites were tightly packed together, making it very hard to see the size and outline of the individual parasite. Characteristic, paired anterior nuclei were, however, easily recognized in these areas. Round aggregates of parasites were sometimes seen among necrotic debris.

Microbiology. No bacteria were isolated from any of the fish, but IPN virus was demonstrated

\section{Case Farm B}

Whitish nodules in liver and kidney, containing large numbers of Hexamita sp., were found in sluggish Atlantic salmon postsmolts (about $300 \mathrm{~g}$ ) investigated at the farm.

\section{Case Farm C}

Large slaughtered Atlantic salmon (3 to $5 \mathrm{~kg}$ ), had large nodules in liver and kidney. Hexamita sp. could be demonstrated in large numbers in histological sections of the nodules.

\section{Case Farm D}

Large slaughtered Atlantic salmon (4 to $5 \mathrm{~kg}$ ), had large boils in muscle, mainly in the caudal part, and some fish also had nodules in the liver and kidney. Large numbers of Hexamita sp. could be demonstrated in smears of the red-brownish, foul-smelling content of the boils in the muscle, and in the imprints of nodules. At slaughter, these fish were filleted, and lesions in the caudal muscles were found in $60 \%$ of the fish from one of the cages.

\section{DISCUSSION}

Hexamita salmonis is generally known as a gut parasite causing catarrhal enteritis in salmonid fry and fingerlings in the warm period of the year (e.g. Ferguson 1989). The parasite is usually found in he upper intestine, including the pyloric caeca. Although the pathogenicity of this flagellate has been questioned, there is no doubt that it may cause high mortality in young fish (Lom 1984). Hexamitid parasites are reported to cause serious infection in various cyprinids and aquarium fish (Amlacher 1970, Molnár 1974) and even systemic infection resulting in granulomatous reactions in the liver and peritoneum of the Siamese fighting fish (Ferguson \& Moccia 1980). These 
latter authors believe that the most likely infection route is by perforation of the gastric wall with subsequent spread to other organs by hematogenous dissemination.

The cases described in this paper represent, to the best of our knowledge, a new and different manifestation of hexamitosis. It is found in postsmolt to adult Atlantic salmon in salt-water under arctic conditions with a low water temperature. The explanation for the susceptibility of preadult and adult fish to acquire such an infection is unknown and is at best speculative. Because only a few hexamitids could be demonstrated in the gut of the salmon examined, we find such an infection route unlikely. In the postsmolts, the only organ in which the parasite was not found was the musculature, while in larger fish, some months later, and at slaughter, the parasites were found in boils in the caudal musculature. The explanation for this change in organ preference is not known. Unless the presence of parasites had been expected, it would have been very difficult to identify the hexamitids in histological sections, especially in liver and kidney.

All the hexamitosed Atlantic salmon on all 4 farms originated from the same hatchery (Fig. 1). Farms A and B were supplied with 2 yr smolts (hatched in 1987) in 1989, Farm C with 1 or 2 yr smolts) in 1988, while Farm D was supplied with 1 yr smolts (possibly 2 yr smolts) in 1989. Thus, all fish may have originated from the same 2 groups of salmon hatched in 1987 and 1988. In 1987, the hatchery bought several hundred thousand alevins from 2 hatcheries further south in Norway. In spite of several investigations, Hexamita sp. has not been found in salmon from the smolt producing hatchery or from wild salmonids in its freshwater supply. Nor have any outbreaks of hexamitosis been reported in other fish farms supplied with smolts from this hatchery in previous and following years. Until further evidence is provided, it seems probable that the fish acquired the parasite in the freshwater phase (possibly as alevins elsewhere), while overt disease was triggered by transportation stress and physiological stress during smoltification and seatransfer. Further work is in progress in order to ascertain the taxonomic status of the parasite, as well as the model(s) of transmission.

During the preparation of this article, our attention was drawn to a new case of hexamitosis in a salt-water fish farm. In this case, Atlantic salmon of 3 year classes are reported to be affected. This fish farm is located less than $200 \mathrm{~m}$ from Farm D and less than $100 \mathrm{~m}$ from a slaughtering facility where the fish from Farm D were slaughtered and processed. Blood and processing water from this facility drains directly into the ocean without treatment. The smolts in the recently affected farm are delivered from a different smolt plant than for Farms A, B, C, and D. In addition to lesions similar to those already described, dermatitis with whitish discolouration of peduncle and caudal fin was present in a majority of the fish investigated. Hexamita $\mathrm{sp}$. was demonstrated in large numbers in smears from the outer surface of these lesions. This indicates a high infection pressure and makes the possibility of transmission in salt water likely.

It is concluded that the described cases represent a new manifestation of hexamitosis caused by a Hexamita species in Atlantic salmon. The disease is possibly associated with stress when the salmon were moved from freshwater to salt-water, as predicted by Lom (1984). However, based on the most recent observation, it is also possible that the disease is caused by a marine Hexamita species. From a diagnostic point of view, it is interesting that the parasites were difficult/impossible to demonstrate by ordinary histological methods unless their presence was suspected or the parasites found by other methods. The gross lesions may have many similarities to other necrotizing lesions in the liver, as well as BKD and other granulomatous diseases (Ferguson 1989).

Acknowledgements. We thank colleagues $\mathrm{G}$. Vik and D. E Ruud for bringing Cases $B, C$ and D to our attention and for valuable information and cooperation

\section{LITERATURE CITED}

Amlacher, E. (1970). Taschenbuch der Fischkrankheiten Fischer Verlag, Jena

Austin, B., Embley, T M., Goodfellow, M. (1983). Selective isolation of Recibacterium salmoninarum. FEMS Microbiol. Lett. 17: 111-114

Culling, C. F. A., Allison, R. T., Barr, W. T (1985). Cellular pathology technique. Butterworth, London

Ferguson, H. W. (1979). Scanning and transmission electron microscopical observations on Hexamita salmonis (Moore, 1922 ) related to mortalities in rainbow trout fry Salmo gairdneri Richardson. J. Fish Dis. 2: 57-67

Ferguson, H. W. (1989). Systematic pathology of fish. Iowa State University Press, Ames

Ferguson, H. W., Moccia, R. D. (1980). Disseminated hexamitiasis in Siamese fighting fish. J. Am. vet. med. Ass. 177 . $854-857$

Kassai, T., Cordero del Campillo, E., Euzeby, J., Gaafar, S., Hiepe, Th., Himonas, C. A. (1988). Standardized nomenclature of animal parasitic diseases (SNOAPAD). Vet. Parasitol. 29: 299-326

Lom, J. (1984). Diseases of Pisces. Diseases caused by protistans. In: Kinne, $O$. (ed.) Diseases of marine animals, Vol. IV. Part 1, Introduction, Pisces. Biologische Anstalt Helgoland, Hamburg, p. 114-168

Mo, T A., Poppe, T T., Iversen, L. (1990). Systemic hexamitosis in salt-water reared Atlantic saImon (Salmo salar L.). Buil. Eur. Ass. Fish Path. 10:69-70

Molnár, K. (1974). Data on the 'octomitosis' (spironucleosis) of cyprinids and aquary fishes. Acta Vet. Acad. Sci. Hung. 24: $99-106$ 
Poppe, T. T. (1990). Hexamita salmonis - Hexamitose. In: Poppe, T T. (ed.) Fiskehelse. Sykdommer, behandling forebygging. John Grieg Forlag, Bergen, p. 228-229 (in Norwegian)

Poynton, S. L. (1986). Distribution of the flagellate Hexamita salmonis Moore, 1922 and the microsporidian Loma salmonae Putz. Hoffman and Dunbar, 1965 in brown trout, Salmo trutla L., and rainbow trout, Salmo gairdneri Richardson, in the River Itchen (U.K.) and three of its fish farms. J. Fish Biol. 29: 417-429

Responsible Subject Editor: D. E. Hinton, Davis, California, USA
Poynton, S. L., Morrison, C. M. (1990). Morphology of diplomonad flagellates: Spironucleus torosa n sp. from Atlantic cod Gadus morhua L., and haddock Melanogrammus aeglefinus (L.) and Hexamita salmonis Moore from brook trout Salvelinus fontinalis (Mitchill). J. Protozool. 37 $369-383$

Sano, T (1970). Etiology and histopathology of hexamitiasis and an IPN-like disease of rainbow trout. J Tokyo Univ. Fish. 56: 23-30

Manuscript first received: November 15, 1991 Revised version accepted: July 29, 1992 